\title{
The Role of Probation Officer in Carrying Out Monitoring to Conduct Measures (Judicial Supervision) in the Issued Judgment by the Competent Court of Juveniles in the Jordanian Law
}

\author{
Dr. Abdel- Kareem Ottallh Al- Karabsheh ${ }^{1 *} \quad$ Dr.Ghadeer Pernec Alzaben ${ }^{2}$ \\ Balqa Applied University, P.O. box 15 Zip Code 19252 Allan, , Jordan
}

\begin{abstract}
This study seeks the role of probation officer in carrying out measures of monitoring to conduct and judicial supervision in the issued judgment by the competent court on juveniles in Jordanian law, with the objective of identifying the mechanism for applying these measures that are not detrimental to freedom for a delinquent juvenile, and the strengths, weaknesses, and obstacles that the conduct supervising faces in applying it in the Jordanian Law.In the Juvenile Law No. 32 of 2014 and the provisions issued by the Ministry of Social Development, the Jordanian legislator has organized a mechanism for conducting supervising in probation officer measures and judicial supervision of a delinquent juvenile in terms of setting out a scheme of monitoring to conduct measures and the procedures to be followed for its implementation and the essential legal period for that provided that it shall not exceed the maximum and writing reports to submit them to the competent judge and the Ministry of Social Development according to the specific legal periods for that, In order to achieve this, the researcher used the analytical approach.This study has concluded several recommendations and results that we hope have achieved the desired goal, and it is taken into consideration by the competent authorities to amend the conduct of juvenile offenders.
\end{abstract}

Keywords: juvenile, juvenile trail, probation officer, judicial supervision, juvenile court.

DOI: $10.7176 / J L P G / 99-11$

Publication date:July $31^{\text {st }} 2020$

\section{Introduction}

Sociologists have been interested in finding appropriate solutions and approaches to deter delinquent juveniles and modifying their conduct, leading to the appointment of useful, successful and appropriate penalties (measures) for the accused convicted by the competent court; Measures to monitoring to conduct or judicial supervision is an appropriate, successful and valid measure for specific groups of delinquent juveniles, whereby the juvenile is rehabilitated and reformed in his natural environment between his family members or an alternate family, after imposing some conditions on him, i.e. restricting his freedom in part, so the juvenile delinquent is removed from the rehabilitation center And reform because it did not achieve the desired objective for reform, and it also saves the costs incurred by the state treasury in spending on the inmate within the reform and rehabilitation centers.

The Jordanian legislator organized monitoring to conduct measures (judicial supervision) in the Juvenile Law No. 32 of 2014, where these measures are issued against a specific category of delinquent juveniles, and he has special provisions in specific articles, so that the provisions of these provisions issued by the competent juvenile judge are followed by an employee of the Ministry Social development is called a probation officer, who is presented in every juvenile court.

In the Hashemite Kingdom of Jordan of all kinds, peace or a beginning, and the probation officer has many tasks in trying juveniles that start from the investigation stage until they end in all stages of the court. In all these stages, he must attend.

A monitoring mission may extend until a judgment is issued by the judge responsible for judicial supervision of a delinquent juvenile, which is the subject of our study. Judicial supervision is represented by conduct measures that are not detrimental for freedom, rather than a prison sentence, implemented by the competent conduct monitor presents in the Juvenile Court

According to a specific applied scheme during A specific period of time to amend the conduct of a delinquent juvenile after studying his or her situation in social and economic terms and the criminal motives that led him to commit the misdemeanor, then he prepares periodic reports on the measures of the delinquent juvenile's conduct according to specific time monitors for each report and submits these reports during these time periods to the competent judge and the Ministry of Social Development.

\section{The objective of study}

The objective of this study is in identifying the chart of monitoring to conduct measures and the mechanism of their carrying out that the conduct to monitor undertakes on the delinquent juvenile after the issuance of a judicial issued from the competent court to place the delinquent juvenile under judicial supervision and 
monitoring to conduct measures not detrimental for freedom according to the text of the Jordanian Juvenile Law No. 32 of the year 2014 and the instructions issued by the Ministry of Social Development .

\section{Study Problem}

The issue of this study is to an identifying of the provisions that regulate the role of the monitoring to conduct in implementing measures to monitoring to conduct of a delinquent juvenile after the issuance of the judicial supervision decision on it from the competent court in accordance with Jordanian law, and reviewing the strengths in order to benefit from them, and reveal the points of defect in order to fix and improve them During the carrying out of monitoring to conduct measures that are not detrimental to freedom, this task is performed by the probation officer appointed by the Ministry of Social Development, who is presented at the Juvenile Court.

\section{Study approach}

In this study, the researcher follows the inductive analytical approach to the provisions of the role of monitoring to conduct in carrying out judicial supervision and probation to conduct measures in the issued judgment by the competent court on the delinquent juvenile in the Jordanian law, and analyzing legal items by a critical approach to identify the strengths and weaknesses of a law, and we will divide the study as follows:

The first topic: The issued judgment by the competent court in monitoring to conduct measures (judicial supervision) on the juvenile.

The second topic: The role of probation officer of carrying out measures to monitoring to conduct on the juvenile

\section{The first topic \\ The issued judgment by the competent court in monitoring to conduct measures (judicial supervision) on the juvenile}

The first requirement: the concept of the juvenile

The Jordanian legislator defined the juvenile in the item of Article (2) of the Jordanian Juvenile Law as: "Anyone who has not completed eighteen years." completed eighteen years however male or female, is called a juvenile, and the Jordanian legislator was not satisfied with that, so the Jordanian legislates has divided the juvenile. in same item into two categories according to the old as follows:

1- The teenager is known as: "Who completed the twelfth and has not completed fifteen years of old.

2- The boy knows that is: "who has completed fifteen years of old and has not completed eighteen years of old.

The second requirement: imposing monitoring to conduct measures on the juvenile

Firstly: Determinants of imposing monitoring to conduct measures on the Juvenile

When setting the juvenile under monitoring to conduct, the Jordanian legislator takes several limitations and considerations that the competent court shall consider, and they are as follows:

1- Appoints the probation officer who supervises the Juvenile during supervising time.

2- Determine the time for the order and the number of a required reports detrimental by the probation officer providing it with the status of the Juvenile.

The objective of the appointment of a probation officer namely by the competent court, leads to motivating the probation officer in his labor, and promotes a sense of responsibility towards the delinquent juvenile, which leads to the success of his mission with montoring to conduct measures that he applies to the juvenile, otherwise he shall expose himself to the legal issue toward of his shortcomings.

Secondly: Cases of imposing monitoring to conduct measures on the juvenile.

In Article (24) of the Juvenile Law, the Jordanian legislator stated a lot of measures of monitoring to conduct (judicial supervision) that are not detrimental for freedom instead of a prison that can be issued by the competent court against the delinquent juvenile, where the law permits the imposition of these measure specifically in a certain cases of a delinquent juvenile, as a follow:

1. Courts may impose one of the measures stated in Article (24) of the Jordanian Juvenile Law if the juvenile commits a felony crime, whether his age group is adolescents (who have completed 12 years and have not completed 15 years) or boys (who have completed 15 and have not completed 18), There is only one case: that the juvenile is committing a felony crime punishable by imprisonment, and there are no discretionary mitigating conditions.

2. Article $(26 / \mathrm{c})$ allowed the court to replace the punishment of a teenage juvenile who committed a criminal crime punishable by temporary hard labor or detention, with one of the measures stated in Article (24) of the Jordanian juvenile law, if mitigating discretionary conditions are available.

The third requirement: carrying out of monitoring to conduct measures and the essential period First: carrying out monitoring to conduct measures 
The imposition of alternative measures that are not detrimental to freedom, carried out by the probation officer under judicial supervision is included in the modern policy of dealing with juveniles, which works to accept society for this category, and embrace them to ensure that they do not repeat their felonies ${ }^{1}$.

And measures that are not detrimental for freedom, alternatives that the judge takes in place of the original and are a prison sentence, so that it is a service that the convict performs for one of the categories of society, or civil society institutions and organizations, or join an educational facility, which the convicted person uses to repair and protect him from harm, provide a service to his community, and issue Under a court provision, fair court guarantees are supervised ${ }^{2}$.

If the Jordanian legislator requires in Article (24) of the Juvenile Law after the conduct monitor who monitors the juvenile during the period of supervising is appointed by the court, a copy of the judicial supervision order is issued to him, and other copies are sent to each of the juvenile and his guardian, or caretaker And if it is decided to impose a judicial supervision order on a female, the conduct monitor must be a female. The judge is also required to implement the measures of conduct after the issuance of the judicial provisions, so the judge undertakes to monitor the carrying out of any measure imposed on the juvenile, and to verify continuously the adherence of the juvenile to the conditions of implementation of the provisions, and he may assign the monitor to do so and submit to an essential reports.

The judge is obligated to specify the period of monitoring to conduct of the juvenile and to specify the number of reports that the probation to conduct must submit to him during the period of the supervising, in accordance with the provisions of the law.

Secondly: The essential legal time for monitoring to conduct measures, their extension and termination.

The Jordanian legislator specified the legal period of monitoring to conduct measures for the juvenile, and did not leave it at the discretion of the judge, whereby the law obligated, according to Article (24/g), the court to issue a judicial oversight measure for a juvenile for a period not exceeding one year, and did not specify the minimum period for this, as he left it to discretion The court.

Whereas, according to Article (24/g/5) of the Juvenile Law, the Jordanian legislator authorized the court that issued a probation officer measures (judicial supervision) with the right of a juvenile delinquent to cancel the measure or modify its duration, based on the request of the probation officer or the juvenile himself or his guardian after reviewing the probation officer report in this regard.

The Juvenile Court is not bound by a specific period in order to be able to terminate the period of monitoring or amend it, so that once the monitor report concludes the court including the recommendation to end the measure, that is, to cancel or amend its duration, the court has the authority to issue its appropriate decision in the case to cancel, amend or reject the recommendation, as authorized by law The request must be submitted by the juvenile or his guardian.

\section{The Fourth requirement: The competent court to impose monitoring to conduct measures}

Jordanian lawmaker concerned with delinquent juveniles. He founded specialized courts to investigate crimes committed by juveniles. Article ( 15 / a) of the Jordanian Juvenile Law stated: "Juveniles are only tried before the competent juvenile courts in accordance with the provisions of this law." In other words, a juvenile is only brought before a juvenile court to receive a penalty or subject to monitoring to conduct measures in accordance with the provisions of the law in the juvenile that acts contrary to law are committed.

Where a magistrate's court is founded ${ }^{3}$ for minors in every governorate, at least, and it specializes in examining violations and misdemeanors whose punishment does not exceed two years and measures of protection or care. And the spatial competence to try juveniles ${ }^{4}$ shall be in accordance with the provisions of Article $(15 / g)^{5}$ of the Jordanian Juvenile Law, according to the location of the crime, the place of residence of the juvenile, the place of his finding, the location of his arrest, or the location of the house in which he was located.

1 - Nadine Al-Nimri, 341 non-custodial judgments for juveniles, an essay published in Al-ghad newspaper, February 8, 2020, Amman, Jordan, Alghad.com/341.

2- Previous Index.

3 - Article (15 / d) of the Jordanian Juvenile Law stated that: A Juvenile magistrate Court shall be founded in every governorate, at least, and it shall be competent to carry out violations and misdemeanors, the punishment of which does not exceed two years, and measures of protection or care.

4 - Article (15/e) of the Jordanian Juvenile Law stated that: "The Juvenile Court shall be founded in the center of each governorate if it needs, and it shall have view to consider felonies and misdemeanors punishable by more than two years."

5 - Article 15 / g of the Jordanian Juvenile Law states: The spatial jurisdiction of the court shall be according to the following:

1. The place of the crime or. 2 . The place of accommodation of the juvenile, the place of his finding, or the place of his arrest, or. 3 . The place of the house where he stayed. 


\section{The second topic \\ The role of probation officer of carrying out measures to monitoring to conduct on the juvenile The first requirement: the concept of monitoring to conduct.}

The second article defines the conduct as: the employee in the ministry ${ }^{1}$ who is responsible for monitoring to conduct of juveniles in accordance with the provisions of this law and the regulations issued pursuant there to. In Article (10) of the Juvenile Law, the Jordanian legislator stated the establishment of an office for probation officer in every court and the office of probation officer in the organizational structure is affiliated with a section in a directorate concerned ${ }^{2}$ with juvenile affairs affiliated to the Ministry of Social Development, from which offices of conduct monitors are branched in every A juvenile court, and each office has a number of probation officer, provided that one of the officer's employees is specialized in psychology or sociology, and the nature of the probation officer is represented in judicial supervision of the, and judicial supervision is defined according to the Jordanian legislator that is: Putting the juvenile in its natural environment under guidance and supervision Taking into account the duties determined by the court ${ }^{3}$.

The item "his environment is the nature that the Jordanian legislator used in Article (24) of the Juvenile Law to define oversight of conduct in general, broad, and incomprehensible terms, and it includes more than one interpretation ${ }^{4}$, because placing the juvenile in his natural environment needs to study all social, economic, psychological, environmental, and family conditions, which This natural environment can be difficult to obtain easily, especially if the event suffers from poverty, family disintegration, or both, and this is not limited to this.

\section{The second requirement: The duties of a monitoring to conduct in implementing the ruling on conduct probation measures.}

The Jordanian legislator did not specify the duties of the probation officer within the provisions of the law, but in Article (44) stated that instructions must be issued by the Minister of Social Development to specify the requirements and information that must be available in the reports of monitoring to conduct, and for this objective instructions were issued in 2015 consisting of ten articles, dealing with The duties of probation officer. Article (3) of the instructions of the Minister of Social Development 2015, which regulates the work of the probation officer, indicated the types of reports submitted by the supervisor, they are either comprehensive or follow-up, and the reports of the juvenile supervision command are considered among the follow-up reports, and article (4) of the same instructions mentioned the foundations that Accordingly, reports are prepared, including maintaining the confidentiality of the information recorded in the reports, the need to submit it within the specified time period, and organizing reports based on field visits to the as much as possible (taking into account), and in the sixth article the information required to be included in the comprehensive reports was covered, and in Article Seven it touched To the information to be mentioned in the follow-up reports (monitoring to conduct reports), and in the eighth article it clarified the role of the juvenile Directorate - in the Ministry of Social Development - in monitoring the work of probation officer.

Article (7) of the instructions issued by the Ministry of Social Development dealt with follow-up reports on the conduct control measure, as follows:

1- Follow-up reports include the following data ${ }^{5}$ : updating the data contained in the comprehensive report, conduct change of the juvenile, change in family circumstances and the surrounding environment, the time period covered by the follow-up report, the measures taken with the juvenile up to the date of preparing the report, the extent of the juvenile's commitment to implement non-freedom penalties, And assess the risk factors for the juvenile who ended his sentence in the event that he is required to be transferred to a person in need of protection and care.

1 - The Ministry, according to the item of Article (2) of Jordanian juvlines, means the Ministry of Social Development.

2 - The Directorate has defined it as the competent organizational unit in the Ministry to follow up on juvenile affairs in accordance with the provisions of this law.

3 - It Defined by Article 24 of the Juvenile Law No. 32 of 2014.

4 - Al-Shami, Azza Adnan Ibrahim, (2016), an Introduced Measures and Penalties in Jordanian Juvenile Law No. 32 of 2014 , Master Thesis submitted to the Faculty of Law, Department of Public Law at the University of the Middle East, p. 65. Akram Zadeh Al-Kordi, Provisions for monitoring to conduct in law Iraqi and Jordanian - a comparative study -, Journal of Comparative Studies Generation, No. 7,. 104.

5 - The report on the status of the juvenile includes the following data and information: A- Personal data about the juvenile, including: (the fourth name, place and date of birth, nationality, national number or identification number for a non-Jordanian, the place of accommodation of the juvenile, the address of permanent accommodation, means of communication With the juvenile or its sponsor). The family status of the juvenile and his family. B- Previous cases, if any. C- Basic data on the current case. D- The educational, health and economic status of the juvenile and his sponsor. E- The situation related to the environment surrounding the event. And - the status of the working juvenile and the work environment. G- Any data related to a special juvenile. H- Sources and means of obtaining information and data. 2- The monitoring to conduct provides a comprehensive social analysis of the data and information mentioned in paragraph A of this article and makes his recommendation based on that analysis. Both the analysis and the recommendation are included in the report. 3- The monitoring to conduct shall attach all the necessary documents to enhance The data contained in the report whenever possible. 4. The probation officer is credited with the report submitted to the relevant authorities on seeking legal assistance and his recommendation on releasing the juvenile as long as possible. 
2- The probation officer in preparing the follow-up report is based on a plan according to a program designed to deal with the juvenile situation, which includes professional intervention services, including social, educational, health, psychological, and recreational activities.

3- The probation officer presents his recommendation regarding the follow-up report, indicating the sources of obtaining information and data and their approaches.

4- The follow-up report is submitted to the competent court every three months or whenever requested to do so. The monitoring to conduct works is subjected to a special program to deal with the juvenile aimed at reforming and rehabilitating him. He has permanent contact with him and submits his recommendations within the report. He also submits reports periodically every three months or upon request to the competent court. It is also obligatory, according to Article 8 of the instructions, to submit monthly reports to the Directorate for Juvenile Affairs at the Ministry of social Development on its work and achievement, and for the latter to monitor the reports submitted by him in terms of quality and adherence to the dates founded in accordance with the provisions of the law.

Moreover, the probation officer is subject to his work, especially the quality of reports and adherence to the directorate of the Ministry, as instructions instruct him to submit monthly reports to the directorate on the progress and completion of his work, and then submit reports to the competent court, in which it is required to be comprehensive of all that is required by law Information, in order to determine the status of the juvenile in terms of its response to these measures, the amendment of its conduct, and rehabilitation.

The third requirement: The penalty imposed by the observer of conduct that violates his duties.

The Jordanian legislator stipulated in Article (24) of the Juvenile Law that in the juvenile that the conduct monitor appointed by the Juvenile Court is unable to implement the judicial supervision order against the juvenile for any condition, the director of the Directorate at the Ministry of Development may request the judge to implement the ruling to appoint another monitor To implement the supervision order, Article $(11 / \mathrm{b})^{1}$ of the Jordanian Juvenile Law dealt with the issue of a conduct monitoring breach of his duties, as it permitted the court to request the replacement of the violator with his duties entrusted to her and to address the minister to take disciplinary measures against him.

Although Article $(11 / \mathrm{b})$ dealt with the issue of questioning the observer who violated his duties during the investigation period, there is nothing to prevent the Juvenile Court from depend on the same article to hold the accountant appointed to carry out the judicial supervision order against the offender if he violates his duties, despite the existence of proposals to include an article of the Jordanian juvenile law, an probation officer that violates his duties is punished, but it remains only suggestions ${ }^{2}$.

\section{Conclusion}

This study was interested in the role of supervising to conduct in carrying out measures to monitoring to conduct and judicial supervision in the issued judgment by the competent court on juveniles in Jordanian law, in accordance with Juvenile Law No. 32 of 2014 and the instructions issued by the Ministry of Social Development with the relation to the mechanism of work of probation officer $g$ in measures to supervising to conduct and judicial supervision On the juvenile delinquent, we ended up in this study to a set of results and recommendations, as follows:

\section{Results}

1. The Jordanian legislator found the conduct monitor of the delinquent juvenile, as he stated the establishment of probation officer in each juvenile court.

2. The Jordanian legislator set the maximum period for monitoring to conduct of the juvenile with a period not exceeding one year, and did not specify the minimum limit for it.

3. The probation officer appointed by the juvenile court specialized in Jordanian law. The decision is sent individually to the probation officer, and he performs the task of monitoring to conduct (judicial supervision) in carrying out of the decision of the competent judge.

4. The Jordanian legislator has created a statement detailing the information that should be recorded in the report. The work of the observer in all its aspects and reports has also been subject to the supervision of the Directorate for the Follow-up of Juvenile Affairs in the Ministry of Development. By requiring the probation officer to submit periodic reports every three months to the court and the public prosecution, which was confirmed by the instructions of the Ministry of Social Development 2015.

1 - Article (11 / b) of the Jordanian Juvenile Law stipulates that: "If the conduct monitor violates any of the duties assigned to him, the court may request a replacement for another and address the minister to take the appropriate disciplinary action against him."

2 - Tarawneh Mohammad, and Al-Marazeeq Issa, (2013), Juvenile Criminal Justice in Jordan, National Center for Human Rights Publications, p. 41 


\section{Recommendations:}

1- The Jordanian Juvenile Law No. (32) for the year 2014 suffers from a legislative deficiency regarding the conduct monitor, as the Ministry of Social Development issued instructions to fill the deficiency defining the tasks, actions and powers of the conduct monitor during the court of juveniles, and for this conditions we call on the Jordanian legislator to intervene to fill the void, and to include these tasks and powers In the juvenile law.

2- We hope from the Jordanian legislator to set the minimum and maximum period for monitoring to conduct on the juvenile, and make it not less than 6 months and not more than a year, as it only set the maximum limit for monitoring to conduct in a year and did not mention the minimum.

3- The necessity of defining the duties of the conduct monitor, and appointing a specific penalty against him if he violates his duties.

4- Amending the instructions issued by the Ministry of Social Development so that monthly reports are submitted to the court by the supervisor on the status of the juvenile instead of (three months) or the period of submission is specified by the judge.

\section{References}

- Akram Zadeh Al-Kordi, Provisions for monitoring to conduct in law Iraqi and Jordanian - a comparative study -, Journal of Comparative Studies Generation, No. 7.

- Tarawneh Mohammad, and Al-Marazeeq Issa, (2013), Juvenile Criminal Justice in Jordan, National Center for Human Rights Publications.

- Al-Shami, Azza Adnan Ibrahim, (2016), an Introduced Measures and Penalties in Jordanian Juvenile Law No. 32 of 2014, Master Thesis submitted to the Faculty of Law, Department of Public Law at the University of the Middle East.

- Nadine Al-Nimri, 341 non-custodial judgments for juveniles, an essay published in Al-ghad newspaper, February 8, 2020, Amman, Jordan, Alghad.com/341.

- The Jordanian Juvenile Law No. (32) for the year 2014

- The instructions of the Ministry of Social Development for the year 2015. 